computed on the columnar system; whereof Tables I. and II. are based on formula (a), and Tables III. and IV. are copies of Mr. Sang's original tables, and are of course based on formula $(b) . *$

I considered it nnnecessary to occupy your space with the $D$ and $N$ columns in connection with Tables I. and III., since these can be so easily referred to in Jones, pages 291 and 292.

I have only in conclusion to suggest, that it will afford much gratification, to any person who will take the trouble, to verify the values of the reversion as given in Table II., by Mr. Farren's formula; but, in order to insure a close and satisfactory approximation, the annuity should be taken from Gray's Assurance and Annuity Tables, or from Thomson's Actuarial Tables, where the value of $\mathrm{A}$ is given to five decimal places. Mr. Sang's reversion may also be verified in a similar manner, by dividing by $\sqrt{1+i}$.

\title{
DAVID CHISHOLM.
}

\section{North British Insurance Office, Edinburgh.}

\section{THE INTEREST QUESTION.}

\section{To the Editor of the Assurance Magazine.}

Sir,-In your last Number, a Mr. Filipowski asks a well known writer how he would, according to his own plan, solve the following problem: $s=$ sum; $d=$ rate of interest; $a=$ amount; $x=$ period or daration. In what time will the sum $s$ amount to $a$, at compound interest? As it is not to be expected that the writer referred to will formally reply to so simple a question, perhaps, as a young Associate of the Institute of Actnaries, I may be allowed to point ont to $\mathrm{Mr}$ Filipowski, who appears from his name and style to be a foreigner, that all our Finglish elementary treatises on algebra tonch on compond interest, and demonstrate that, if $s(1+d)^{*}$ is to equal $a$, that $x$, as a period or duration, will equal the logarithm of $a$ divided by the logarithm of $s(1+d)$. I may also direct Mr. Filipowski's attention to a work published in 1816, entitled Investigation of the Errors of all Writers on Annuities, in their valuation of half yearly and quarterly payments, \&c., \&c.; by Wm. Ronse. Mr. Ronse, like Mr. Filipowski, takes up the old notion of D'Alembert, embodied by Mr. Smart in his tables, of nsing the geometrical mean of $(1+d)^{\frac{1}{2}}$ between 1 and $(1+d)$, instead of the arithmetical mean of $\left(1+\frac{d}{2}\right)$, as in common use; but as the notions expressed by the two cases are very different in theory, $\mathrm{Mr}$. Corbanx has pointedly said, in his Doctrine of Compound Interest, p. 64, "This writer has taken great pains merely to prove truisms." Accordingly, all the best modern interest tables, like those of Mr. Peter Hardy and Mr. Rance, are framed for half yearly and quarterly interest on the same formule as those of Corbanx, and not npon the antiquated ones of D'Alembert and Smart, so severely criticised by Mr. Milne and the writer in the Penny Cyclopadia.

\section{Yours respectfally,}

\section{A YOUNG ASSOCIATE.}

* See "Original Tables," pp. 89-92. 